\title{
Mass barium carbonate poisoning with fatal outcome, lessons learned: a case series
}

\author{
Aniruddha Ghose*1, Abdullah Abu Sayeed ${ }^{1}$, Amir Hossain ${ }^{1}$, \\ Ridwanur Rahman², Abul Faiz ${ }^{3}$ and Gofranul Haque ${ }^{1}$
}

Address: ${ }^{1}$ Department of Medicine, Chittagong Medical College, (4000), Chittagong, Bangladesh, ${ }^{2}$ Department of Medicine 'aheed Suhrò, wardy Medical College, Dhaka, (1207), Bangladesh and '3epartment of Medicine, Sir Salimullah Medical College, Dhaka, (1000), glade;

Email: Aniruddha Ghose* - anrdghs@yahoo.com; Abdullah Abu Sayeed - abdullahdr25@yahoo.com;

Amir Hossain - amir_hossain_ctg@yahoo.com; Ridwanur Rahman - ridwanurr@yahoo.com; Abul Faiz - drmafaiz( omail.con);

Gofranul Haque - gofranul2006@yahoo.com

* Corresponding author

Published: 16 December 2009

Cases Journal 2009, 2:9327 doi:10.1/86/1757-1626-2-9327

This article is available from: http://www.casesjournal.com/content/2/I/9327

(c) 2009 Ghose et al; licensee BioMed Central Ltd.

This is an Open Access article distributed under the terms of the Creative Commons Attributirn Ll, ense (http://creativecommons.org/licenses/by/2.0), which permits unrestricted use, distribution, and reproduction in any medium, provided the ol iginal work is properly cited.

\begin{abstract}
Introduction: Barium, a heavy divalent z"lalin, netal has long been known to cause human toxicity. The common mode is accidental ingestion the co. hon compound is Barium carbonate. Here we report an incident of food poisoning in 27 la $v$ en cement personnel with rapidly developing sequelae and a high mortality due to ingestion of Ba lum carbori, contaminated flour.

Case presentation: One mi ight, 27 adult males were rushed to emergency department of Chittagong Medical College Hospital wi ahd,minal pain, vomiting, loose motion, cramps and generalized paraesthesia. The ailme tarted 1-2 hours after Iftar (evening meal to break day long fast during Ramadan) which included fr' restless, agitater. repo ted weakness of limbs and were unable to walk. 10 had hypotension. 22 had rapid and sha! , r $r$-imation. 5 had carpopedal spasm. Different grades of limb weakness were noted with loss of ter.un jt Ten (NI2) patients had hypokalaemia, three had hypoglycaemia, 4 patients had high creatin - nase. Ely _rocardiogram showed flat ST with $U$ waves in 4 patients. Potassium containing intravenou. "uid and Oxygen was administered. Due to limited availability of mechanical ventilators Datients were, ut on artificial respiration using Ambu bag; manually maintained by doctors, paramedics and or lant. Four patients were transferred to another hospital for mechanical ventilation. A total of 12 pa. ts jied over next 16 hours, 4 within 3 hrs. Other patients gradually improved. Chemical analysis of the v, mitus, blood and flour used for preparation of meal revealed the presence of Barium. It was assumed $c$ the flour was contaminated with the similar looking Barium carbonate powder which was kept in the kitchen as a rodenticide.
\end{abstract}

Conclusion: This event exemplifies the weakness of usual health care facility in resource poor settings to cope with this kind of massive poisoning event. The multiple reported incidences of accidental Barium poisoning due to unintentional mixing with food signifies the fact that the use and availability of Barium carbonate should be restricted. We hope to draw attention to this relatively uncommon poisoning and to the need for development of poison information centre in resource poor countries. 


\section{Introduction}

Barium, a heavy divalent alkaline metal has long been known to cause human toxicity. Currently approximately 40 of these salts are being used in industries [1]. Insoluble Ba sulphate is used as radiographic contrast medium. Carbonate, hydroxide and chloride forms of barium are used in pesticides. Ba carbonate is also used for glazing pottery while barium sulphide is used in depilators for external application [2].

Stomach acid converts the Ba carbonate to Ba chloride and intestinal absorption is similar to calcium and excretion is mainly faecal. Peak serum level occurs 2 hours after ingestion with an elimination half life of 3.6 days. The systemic effects of Barium are linked with two modes of action: direct muscular stimulation (skeletal, cardiac, and smooth), and hypokalaemia $[3,4]$. The latter effect is associated with the ability of the barium ion to block potassium $(\mathrm{K}+)$ channels and interfere with passive $\mathrm{K}+$ diffusion $[4,5]$. All water and acid soluble Ba salts are poisonous. Case reports implicating several compounds of Ba (eg. Carbonate, chloride) have been reported in literature. The common mode is accidental ingestion and the common compound is Ba carbonate. Accidental mixing of $\mathrm{Ba}$ carbonate with food and poisoning out of it has been reported as early as in the $2^{\text {nd }}$ world war [6]. Ba Carbonate exposure has not been previously reported In Bangladesh. The use of Ba carbonate as rodenticide and subse poisoning is relatively unknown to the medical comn. nity in Bangladesh. We report here an incire. of fooc poisoning in 27 law enforcement personnol with vidly developing sequelae and a high mortali y due to the ngestion of Ba carbonate contaminated flor We hoje to draw attention to this relatively unknown ncommon presentation and to the need to velop a poison information centre in resource poor colnan.

\section{Chronology and descri, on canses}

On the evening of $1 / \mathrm{ch} \Lambda$ Pmber 2001, at around $6 \mathrm{pm}$, 27 armed police $\mathrm{f}$ connel a camp in a remote area of Chittagong Hili Trao imultaneously developed abdominal pain and vomitin, followed by loose motions all within 306 minutes of each other. Their symptoms progroned $\mathrm{id} / y$, and subsequently they developed cr nps, pains, generalized paresthesia, most marked in the around $10 \mathrm{pm}$ they were taken to a nearby hospls where they were given oral rehydration and IV fluids and were referred to Chittagong Medical College Hospital. They arrived at the emergency between 11:45 $\mathrm{pm}$ to $12: 30$ am and were quickly transferred to medicine ward. All 27 patients were interviewed and examined. It was found that they all had taken Iftar (the evening meal to break day long fast during the month of Ramadan) consisting of traditional food items which included beans, pulse, and fried vegetables coated with a flour paste. The ailment started 1-2 hours after the meal.
On admission all of them presented with features of acute gastroenteritis. Twenty of them were restless and agitated. Raised blood pressure (SBP 150-170, DBP 90-110) was noted in 5 patients, 10 were found to have BP less than $100 / 70 \mathrm{~mm} \mathrm{Hg}$. Rapid and shallow respiration were found in 22 patients. Twenty two patients reported weakness of all four limbs and were unable to mov/ or walk. Five patients had carpopedal spasm. Differen ro les bf limb weakness were noted with loss of tendon je. Gastric aspiration, stool, and blood samp' s were col ected from 24 patients. ECG was done in 12, tient . Serum electrolytes, CPK and creatinine were me red in 12 patients. Ten patients had hypol laemia $\left(\mathrm{K}^{+}<3.5\right)$ ranging from 1.87 to 3.05. Thr we hvo glycaemic. Four patients had high CPK cut of value $190 \mathrm{u} / \mathrm{l}$ ). ECGs showed flat ST segmer with $\mathrm{U}$ Aves in 4 patients, one patient had ECG feat res embling ischaemia, three had left ventricular by trophy,

Intravenous flù 'Cnm $K^{+}$were given to all patients. Oxygen supplementat / with nasal prongs was established. Regular I vo ring of vital signs, fluid balance was arranged. Seven patients rapidly deteriorated. Four of tham died ythin $3 \mathrm{hrs}$ of admission due to respiratory par. sis. Due to limited availability of mechanical ventitors patients were put on artificial respiration using a bags; manually maintained by doctors, paramedics arid attendants. Four patients were transferred to Combined Army Medical Hospital for mechanical ventilation. In total 12 patients died over next 16 hours; all apparently due to respiratory failure. Other patients gradually improved over time and discharged subsequently. Their recovery was uneventful.

Chemical analysis of the vomitus and blood samples from the victims revealed presence of Barium. Barium was also detected in the sample of flour used for preparation of meal. It was assumed that the flour was contaminated with the similar looking Ba carbonate powder which was kept in the kitchen as a rodenticide.

\section{Discussion}

The patients in this event passed though several stages. Initially all developed gastroenteritis, subsequently nervous system was affected as evident by tingling, numbness and limb weakness due to neuromuscular paralysis and later on some of them developed respiratory muscle paralysis. Suspicion of food poisoning was made from the clustered nature of these cases and the temporal relationship with meal. With the rapid onset of features of gastroenteritis and neuromuscular paralysis the differential diagnoses in this situation were limited. Ciguetra and paralytic shellfish were excluded from the list of consumed food items. The other closely related conditions were gastroenteritis with hypokalaemic paralysis and Botulism, but the prom- 
inent sensory symptoms could not be explained by any of these. Botulism usually takes a longer time to develop [1].

Similar incidences of mass food poisoning due to Ba Carbonate have been reported previously. In 1945 in a British army regiment $\mathrm{Ba}$ carbonate was identified as the agent causing poisoning in 89 soldiers. Two outbreaks of Ba Carbonate poisoning happened in Israel in a large number of people in different villages [7]. Johnson HC reported seven cases of Ba Carbonate poisoning occurring in one family [1]. In all of these cases the common factor appeared to be the accidental mixing of Ba Carbonate with foods. Ba carbonate powder has a similar appearance to flour and flour was used to prepare these food items. The clinical features of our patients also resemble those in previous reports. In all these events, features suggesting gastroenteritis were the presenting complaints with patients subsequently developing muscle weakness and cardiac rhythm abnormalities. One striking difference is that we detected no rhythm abnormality in our patients.

In this series 12 patients died. This is a much higher mortality than in any other previously reported case series and is surprising given the greater expected physical reserve of armed force personnel compared to general population. Another feature unique to this group is that they were all fasted for about 12 hours prior to poisoning. The lon, rast and fluid depletion might have accelerated the absør of Ba carbonate and a larger than normal amou it of fo may have been consumed in one sitting follo $v$. the fast This may explain the rapid involvement of res muscles leading to respiratory failure $y$ ith hypokalaemia contributing. Due to limited resource e were unable to perform all the necessary investigations all a tients. For those who survived (N16), sever ctors might have contributed, e.g. less amount inges ec, iter intravenous potassium replacement an fecti e respiratory support.

A high index of suspicio Tlong with correlation of the clinical events $\%$ the cir amstantial evidence is very important in diagno and management of uncommon poisonings. After the in , lal gastric lavage, further management is $1 \mathrm{c}$ e sujportive [8]. Endotracheal intubation and monan $1 \mathrm{ventilation}$ is indicated if respiratory failur int venes. sodium sulphate given orally has been cla a educe absorption by forming an insoluble, nonto. Ba sulphate. Intravenous magnesium and potassium chloride are used to correct hypomagnesaemia and hypokalaemia, respectively. Renal replacement therapy (intermittent haemodialysis [9-11] or continuous venovenous haemodiafiltration [3] shortens the half-life of barium and is reported to be effective in severe barium poisoning and should be considered early in the management.
Another very important aspect of this event is that it signifies the need for further development of traditional health care facilities to cope with this kind of massive poisoning event. The sheer number of patients presenting in an acute emergency condition in an ordinary medicine ward was not something easily dealt with. The on duty doctors were out numbered. We tackled the situation by summoning doctors and consultants from other units in th i dle bf the night. Due to the limited availability of res, atory support, some patients had to be tran rred to ai, other hospital and others were managed br ma l ver cilation. If we had more equipped ICU or ADU facis s the fatalities would probably have been less. During the initial management of these case we a a loss initially regarding the possible differe al diagnoses and necessary laboratory investic ions. Th inportance of a poison information centre $\mathrm{o}$ ta $\mathrm{l}$ this kind of situation has been elaborately - hlightec y Deng JF et al [12]. Should there be an $c$ abl hed poison information centre we could have us the resources and the management would hre been $\mathrm{b}$ cer with a more favorable outcome.

\section{Conclusich}

Tho multipl reported incidents of accidental Ba poisoning $e$ to unintentional mixing with food signifies the act $\mathrm{t}$ at the use and availability of Ba Carbonate should D stricted. The proposal of colouring the powder of Ba Carbonate so that it can not be mistaken as flour demands serious appreciation from the concerned authority. Medical professionals should also be aware of the possibility of such accidents and be cautious in suspicious cases. The essential role of a resourceful poison information centre in aiding the diagnosis, assisting with laboratory confirmation and management of such an incident can not be over stated.

\section{Abbreviations}

Ba: Barium; CPK: Creatine kinase; DBP: Diastolic blood pressure; SBP: Systolic blood pressure.

\section{Consent}

Written informed consent was obtained from the patients for publication of this case report. A copy of the written consent is available for review by the Editor-in-Chief of this journal.

\section{Competing interests}

The authors declare that they have no competing interests.

\section{Authors' contributions}

AG attended the patients, involved in collection of data, literature search, and manuscript writing. AAS involved in searching literature and manuscript editing. AH performed data collection, and manuscript editing. MRR, 
MAF and MGH were the consultant physicians attending the patients, and involved in editing the manuscript.

\section{Acknowledgements}

We are thankful to the doctors and nursing staff of medicine unit, Chittagong Medical College Hospital, Chittagong who managed the cases.

We thank Dr. Samuel T Douthwaite MBChB, MRCP, MTROPMED for his help during preparation of the manuscript.

\section{References}

I. Johnson $\mathrm{CH}$, VanTassell VJ: Acute barium poisoning with respiratory failure and rhabdomyolysis. Ann Emerg Med 1991, 20(10): I |38-I | 42.

2. Goel A, Aggarwal P: Pesticide poisoning. Natl Med J India 2007, 20:182-191.

3. Koch M, Appoloni O, Haufroid V, Vincent JL, Lheureux P: Acute barium intoxication and hemodiafiltration. J Toxicol Clin Toxicol 2003, 4 I (4):363-367.

4. Downs JC, Milling D, Nichols CA: Suicidal ingestion of bariumsulfide-containing shaving powder. Am J Forensic Med Pathol 1995, 16:56-61.

5. Walter SJ, Shirley DG, Folkerd EJ, Unwin RJ: Effects of the potassium channel blocker barium on sodium and potassium transport in the rat loop of Henle in vivo. Exp Physiol 200I, 86:469-474.

6. Morton W: Poisoning by Barium Carbonate. Lancet 1945, 2:738-739.

7. Lewi Z, Bar-Khayim Y: Food-Poisoning from Barium Carbonate. Lancet 1964, 2:342-3.

8. Worthley LI: Clinical toxicology: part II. Diagnosis and management of uncommon poisonings. Crit Care Resusc 2002, 4:216-230.

9. Thomas M, Bowie D, Walker R: Acute barium intoxicatic a following ingestion of ceramic glaze. Postgrad Med 99 74(875):545-546.

10. Wells JA, Wood KE: Acute barium poisoning rated $w_{1}$ hemodialysis. Am J Emerg Med 200I, I 9(2): $175-171$.

II. Schorn TF, Olbricht C, Schüler A, Franz A, Wittek K Balk. Hausmann E, Wellhoener HH: Barium carbonate incuxicatio. Inten-
sive Care Med I99I, I 7(I):60-62.

12. Deng JF, Jan IS, Cheng HS: The essential $r$ e of a po'son center in handling an outbreak of barium carl ate po soning. Vet Hum Toxicol 1991, 33(2): 173-175.

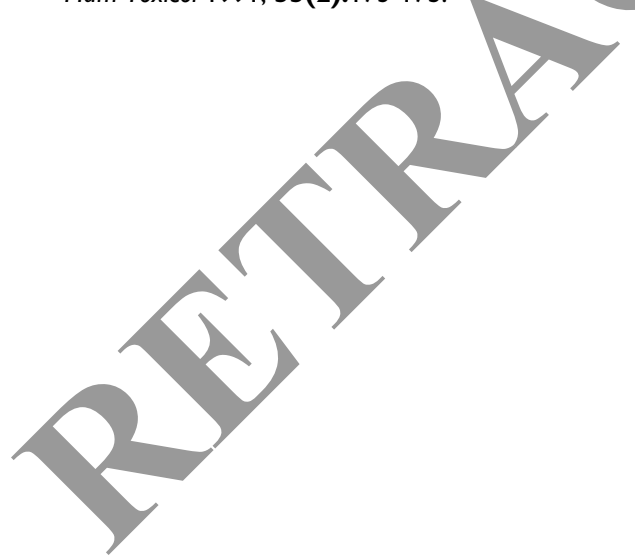

Publish with Bio Med Central and every scientist can read your work free of charge

"BioMed Central will be the most significant development for disseminating the results of biomedical research in our lifetime. "

Sir Paul Nurse, Cancer Research UK

Your research papers will be:

- available free of charge to the entire biomedical community

- peer reviewed and published immediately upon acceptance

- cited in PubMed and archived on PubMed Central

- yours - you keep the copyright

Submit your manuscript here:

http://www.biomedcentral.com/info/publishing_adv.asp
BioMedcentral 